\title{
La producción de alfarería Belén del Valle de Hualfín (provincia de Catamarca, Argentina): un acercamiento a partir de la petrografía cerámica
}

\author{
María Emilia Iucci y Marta Alperin \\ Recibido 03 de diciembre 2018. Aceptado 07 de junio 2019
}

\begin{abstract}
RESUMEN
Se presentan los resultados del análisis petrográfico de 69 cortes delgados de cerámica Belén del Valle de Hualfín como un aporte para el estudio de las prácticas alfareras y de la organización de su producción. La muestra se obtuvo en seis poblados arqueológicos ubicados cronológicamente entre los siglos XIV y XVI. Se registran diferentes atributos de la pasta y se cuantifican las inclusiones en los niveles composicional y textural. Los datos expresados como porcentajes se analizan utilizando métodos estadísticos para datos composicionales y la búsqueda de grupos se realiza con análisis cluster. La muestra mayoritaria está compuesta por sedimentos arenosos que llevan a considerar pautas de producción no estandarizadas pero relativamente estructuradas. Los escasos ejemplares con tiesto molido y con altas proporciones de fragmentos pumíceos permiten discutir su producción en el contexto de las interacciones entre poblaciones en la escala regional y de la expansión del Estado inkaico.
\end{abstract}

Palabras clave: Cerámica Belén; Petrografía; Organización de la producción; Período Tardío; Datos composicionales.

\begin{abstract}
BELÉN POTTERY PRODUCTION IN HUALFíN VALLEY, CATAMARCA PROVINCE, ARGENTINA: A CERAMIC PETROGRAPHY APPROACH. The results of the petrographic analysis of 69 thin sections of Belén ceramics from Valle de Hualfín are presented as a contribution to the study of pottery practices and the organization of production. The sample was obtained from six archaeological sites located chronologically between the fourteenth and sixteenth centuries. Different attributes of the paste were recorded and the inclusions in the compositional and textural levels quantified. The data expressed as percentages were analyzed using statistical methods for compositional data and the search for significant groups was carried out through cluster analysis. Most of the sample consists of sandy sediments, which might indicate nonstandardized production but with a relatively structured pattern. There are few specimens with grog and with high proportions of pumiceous fragments, which enables a discussion of their production in the contexts of interactions between populations on a regional scale and the expansion of the Inka state.
\end{abstract}

Keywords: Belén ceramics; Petrography; Pottery production; Late period; Compositional data.

\footnotetext{
María Emilia lucci. Consejo Nacional de Investigaciones Científicas y Técnicas (CONICET). Laboratorio de Análisis Cerámico, Facultad de Ciencias Naturales y Museo, Universidad Nacional de La Plata, Argentina. Calle $64 \mathrm{~N}^{\circ} 3$ (I900), La. Plata, Argentina. E-mail: emiliaiucci@fonym.com.ar

Marta Alperin. Cátedra de Estadística. Facultad de Ciencias Naturales y Museo, Universidad Nacional de La Plata, Argentina. Calle $64 N^{\circ} 3$ (1900), La Plata, Argentina. E-mail: alperin@fonym.unlp.edu.ar
} 


\section{INTRODUCCIÓN}

La cerámica Belén es una de las manifestaciones alfareras que tuvieron amplia extensión durante la época tardía en la región valliserrana del noroeste argentino, y el tema de cómo era producida ha sido abordado desde diferentes aproximaciones (Wynveldt 2009; Puente 2012; Puente et al. 2014; De La Fuente et al. 2015; lucci 2016, entre otros). En particular, el análisis de las pastas en los niveles de microscopía óptica y composición química ha permitido establecer correspondencias generales entre los ambientes geológicos regionales y los materiales constitutivos usados en la manufactura cerámica (Wynveldt 2009; Zagorodny et al. 2010; Puente 2012; Puente et al. 2014; De La Fuente et al. 2015; lucci 2016). Por otro lado, más allá de algunas regularidades halladas en estos estudios, las variaciones en el conjunto han Ilevado a postular que la preparación de la pasta no se basaba en recetas estrictas o estandarizadas.

Con el objetivo de realizar un aporte al estudio de las prácticas alfareras en la etapa de la preparación de la pasta y de la organización de la producción de la cerámica Belén, se presenta el análisis petrográfico de una muestra de 69 cortes delgados de diversos poblados del Valle de Hualfín, ubicados cronológicamente entre finales del siglo XIV y principios del XVI. Se realiza una caracterización general de la pasta y un análisis de la composición y textura de las inclusiones. A partir de métodos estadísticos de datos composicionales (i.e., datos expresados como porcentajes o proporciones) (Aitchison 1986), se buscan patrones de agrupación con significación para analizar la forma en la que fueron hechos los objetos cerámicos y la organización de la producción alfarera.

\section{LA CERÁMICA BELÉN EN EL PAISAJE TARDÍO DEL VALLE DE HUALFÍN}

El sector geográfico que en la tradición arqueológica se denomina Valle de Hualfín se localiza en la región centro-oeste de la provincia de Catamarca y se extiende desde la localidad actual de Los Nacimientos, en el norte, hasta la de Puerta de San José, por el sur (Figura 1). El valle desciende desde los $2200 \mathrm{msnm}$ al norte a los 1400 en el sur, mientras que las sierras más altas alcanzan los $4000 \mathrm{msnm}$. Geológicamente, el valle pertenece al sector norte de las Sierras Pampeanas noroccidentales y forma parte de la subcuenca Hualfín, porción sudoeste de la gran cuenca Santa María-Hualfín (Muruaga 2001). El basamento cristalino, de edad precámbrica-cámbrica, está constituido por rocas metamórficas de bajo grado a medio (generalmente

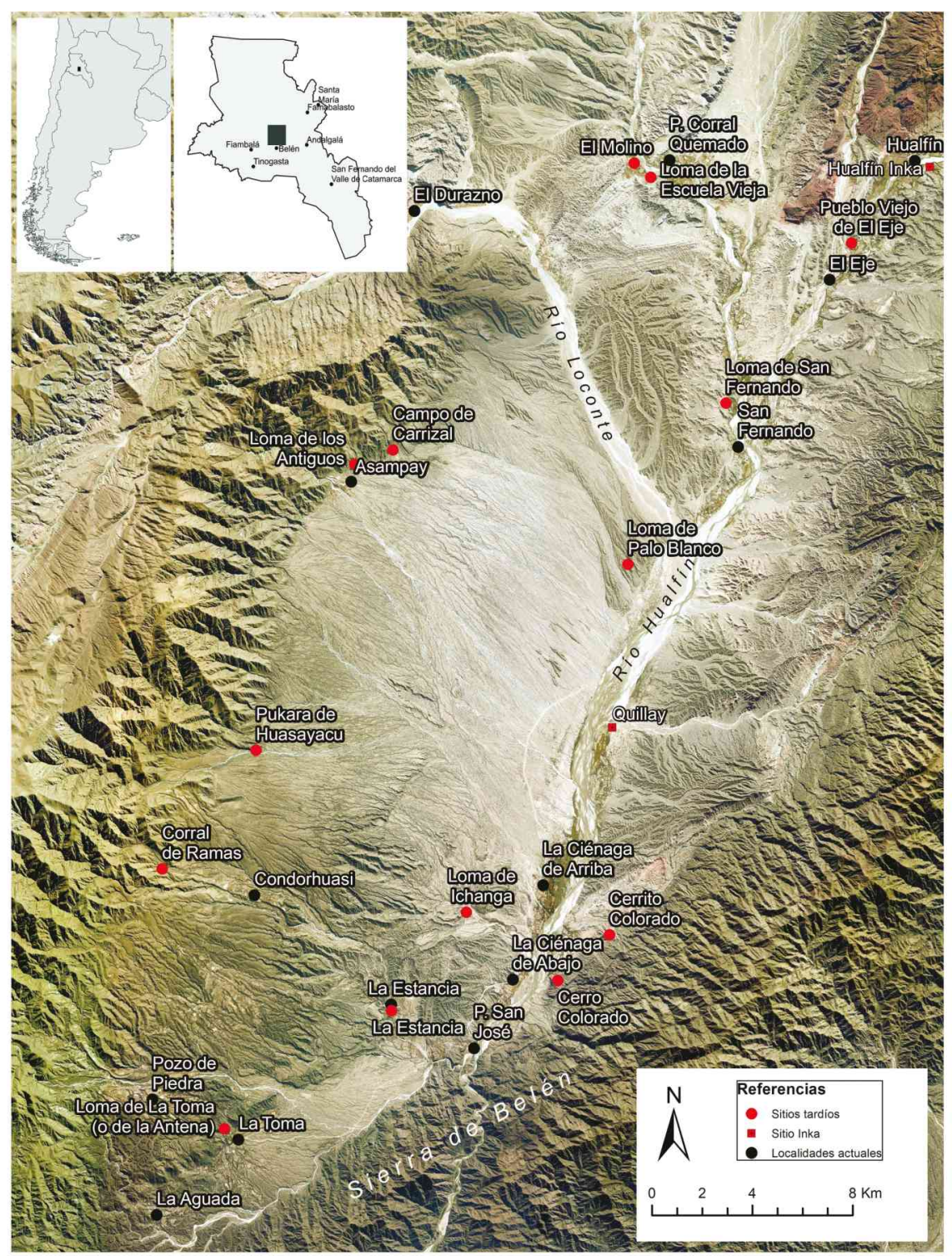

Figura 1. Mapa del Valle de Hualfín con la indicación de los sitios de donde se extrajo la muestra cerámica bajo estudio. 
transformadas por inyección ígnea) intruidas por granitos y granitoides que constituyen cuerpos batolíticos parcialmente milonitizados. Los valles intermontanos están cubiertos por una importante secuencia terciaria de sedimentos clásticos continentales (arenosos y conglomerádicos) intercalados por sedimentos volcánicos y cubiertos por sedimentos cuaternarios con depósitos de piedemonte de poco espesor -Punaschotter y de acarreo- (Muruaga 2001; Bossi y Muruaga 2009). La cubierta vegetal es escasa y los suelos están poco desarrollados, de modo tal que los sedimentos que podrían haber sido usados en la manufactura cerámica presentan una amplia disponibilidad.

Los asentamientos con alfarería Belén se encuentran sobre lomadas de hasta 150 metros de altura y en antiguas terrazas de inundación. Los primeros, conformados por entre 15 y alrededor de 100 estructuras de piedra, fueron definidos como "poblados protegidos" en función de las barreras para el ingreso y la visibilidad del entorno, que serían clave en momentos de conflicto intergrupal (Wynveldt et al. 2013). También se registran construcciones aisladas cercanas a los cursos de agua y áreas con andenes de cultivo (Valencia et al. 2009). Las dataciones obtenidas para el conjunto de sitios se concentran en el siglo XV y se extienden entre finales del siglo XIV y el siglo XVI (Wynveldt et al. 2017). En este sentido, una parte importante del desarrollo histórico de estas poblaciones fue contemporáneo de las ocupaciones inkaicas de la zona, evidenciadas por los sitios Quillay y Hualfín Inka dentro del valle, y por la instalación de El Shincal, ubicada al sur, en la actual localidad de Londres (Raffino 1988; Lynch 2011; Spina et al. 2017). La cultura material de la mayor parte de los sitios locales raramente revela la presencia estatal, y el límite entre un momento preinka y uno inka no está definido, de modo tal que la índole de las relaciones sociopolíticas entre estas poblaciones y el Estado es una problemática aún en discusión.

Los trabajos sobre el paisaje tardío del valle se han enfocado en el estudio de la vida cotidiana situada en los procesos sociopolíticos (Wynveldt 2009; Balesta et al. 2011; lucci 2016). Desde esta óptica, la organización de la producción, los ritmos de los procesos de manufactura, los objetos y su participación en las prácticas humanas, además de ser foco de interés para los estudios cerámicos en general, contribuyen a la configuración de redes de relaciones de escala más amplia. Dónde se ubicaban los talleres de manufactura cerámica, cuál era la escala de la producción, quiénes eran los artesanos, cómo se organizaban para producir y si existieron transformaciones en la organización y en los modos de hacer cerámica que acompañaron los cambios de las coyunturas sociopolíticas, se encuentran entre los problemas que deben ser analizados. Desde los estudios cerámicos se han discutido variables para el abordaje de estas problemáticas (Blackman et al. 1993; Costin y Hagstrum 1995; Dietler y Herbich 1998; Longacre 1999; Arnold 2000; Roux 2003, entre otros), como por ejemplo, la cantidad y distribución de los lugares de fabricación, pasibles de ser inferidos mediante la caracterización de la composición y del grado de uniformidad de las pastas cerámicas. En general, bajo la observación de que la repetición y la experiencia de los artesanos conducen a una regularidad y consistencia en la técnica de manufactura, estos autores siguen la premisa de que menos lugares de manufactura y pastas más uniformes implican menos manos productoras pero más especializadas.

La cerámica Belén, junto con la alfarería ordinaria que la acompaña en todos los contextos, es una de las manufacturas artesanales más conspicuas de las producidas y usadas por los antiguos habitantes de la época en el valle (lucci 2016) y zonas aledañas como el Valle de El Bolsón (Puente 2012), de Tafí (Páez y Sardi 2014) y de la región de Fiambalá (Basile 2009; De La Fuente 2011). En el Valle de Hualfín, las distintas morfologías -pucos, tinajas y ollas (sensu Wynveldt 2009)- se encuentran con variado grado de representación, desde fragmentos aislados hasta piezas enteras, y en diversos tamaños, en conjuntos numéricamente importantes en la superficie de todas las instalaciones, en el interior de los recintos y en los entierros de los antiguos habitantes. Los estudios morfológicos, métricos y de huellas de manufactura (Wynveldt 2009; lucci 2016) indican que cada tipo de forma presenta regularidades morfológicas y de proporción características, aunque el grado de variabilidad no permite postular una manufactura estandarizada (lucci 2016), en términos de los resultados de los estudios morfométricos de referencia (Costin y Hagstrum 1995; Longacre 1999; Roux 2003). Los estudios basados en análisis químicos (Puente et al. 2014; lucci 2016) muestran un panorama general coincidente con el uso de diversas fuentes de materias primas y, junto con otras líneas de evidencia, se ha establecido que la producción se extendía en diversos locus de manufactura. Las pastas analizadas bajo microscopio petrográfico (Zagorodny et al. 2010; 
Puente 2012; De La Fuente et al. 2015; Iucci 2016, entre otros) exhiben mayoritariamente inclusiones de sedimentos de arena y limo. La composición de los sedimentos guarda una importante similitud en el nivel regional, pero registra algunas variaciones en las proporciones de sus componentes.

En este contexto, se presenta la línea de estudio de la petrografía Belén a partir de la caracterización general de las pastas y de la búsqueda de patrones en las características de los elementos componentes para analizar la manufactura y la organización de la producción alfarera, considerando el aporte de la estadística de datos composicionales para el análisis.

\section{MATERIALES Y MÉTODOS}

La muestra (Tabla 1) incluye 69 láminas delgadas de tinajas, pucos y ollas Belén recuperadas en superficie y en la excavación de siete sitios caracterizados como poblados protegidos (Valencia et al. 2009; Wynveldt 2009; Balesta et al. 2011; Iucci 2016). Todos los cortes corresponden a piezas diferentes. Para la conformación de la muestra se buscó, en el caso del material de excavación, la representatividad del conjunto de piezas Belén que se hallaron en cada estructura en sus distintos grados de completitud. El material de superficie se incorporó para ampliar la muestra y añadir cerámica de sitios que no cuentan con cerámica de excavación. El principal criterio para la elegibilidad del fragmento a cortar fue el de determinar con certeza el tipo cerámico, el sector del cuerpo y su orientación en la pieza. Una parte importante de la muestra había sido analizada previamente (Wynveldt 2009; lucci 2013 y 2016). Los cortes se realizaron en sentido horizontal, de modo perpendicular a la pared de la vasija, siguiendo la orientación del plano de la boca.

\section{Observación y registro de los cortes delgados}

La aproximación técnica al análisis petrográfico se elaboró a partir de una serie de trabajos de referencia (Middleton et al. 1985; Stoltman 1989; Freestone 1991; Johnson 1994; Quinn 2013). Se consideraron (i) las características generales de la pasta; y (ii) las características y composición de las inclusiones de la fracción de tamaño arena $(0,062$ $\mathrm{mm}-2 \mathrm{~mm}$ ).

\section{i) Características generales de la pasta}

La caracterización general de la pasta se realizó utilizando criterios de comparación visual y criterios cuantitativos. Para los primeros se tuvieron en cuenta la orientación general, forma de las cavidades, proporción de arcilla-limo y composición de los limos. Para los segundos se determinaron las proporciones de matriz, cavidades e inclusiones con granulometría de tamaño arena:

a) Orientación general de la pasta: en referencia a la disposición espacial de las cavidades e inclusiones, se utilizó una escala de cuatro categorías: muy buena: con grietas e inclusiones orientadas con el sentido longitudinal del corte; buena: cuando se observa una tendencia general de las grietas e inclusiones a estar orientadas; regular: solo algunas grietas e inclusiones están algo orientadas; y mala: cuando no se observan elementos orientados.

b) Cavidades o poros: se identificaron en el plano del corte petrográfico en forma de grietas (cavidades de forma alargada), cavidades irregulares sin una forma definida, y una combinación de los dos tipos (mixtas).

c) Proporción arcilla-limo: se analizó y denominó en función de las cantidades y predominio relativo de arcilla y limo.

d) Composición de la fracción limo.

e) Porcentajes de matriz-cavidad-inclusiones (porcentajes $\mathrm{MCl}$ ). Se contaron las cavidades e inclusiones de tamaño mayor o igual a $62 \mu \mathrm{m}$ en

\begin{tabular}{|c|c|c|c|c|c|c|c|c|}
\hline \multirow{3}{*}{ Sitio y código de sitio } & \multicolumn{2}{|c|}{ Procedencia } & \multicolumn{5}{|c|}{ Forma y sector } & \multirow{3}{*}{$\begin{array}{c}V \\
\text { por } \\
\text { sitio }\end{array}$} \\
\hline & \multirow{2}{*}{ Excavación } & \multirow{2}{*}{ Superficie } & \multicolumn{2}{|c|}{ Puco } & \multicolumn{2}{|c|}{ Tinaja } & \multirow{2}{*}{$\begin{array}{c}\text { Olla } \\
\text { C }\end{array}$} & \\
\hline & & & C & Bo & $\mathrm{C}$ & Bo & & \\
\hline Loma de la Escuela Vieja (LEV) & 5 & 11 & 1 & - & 9 & 5 & 1 & 16 \\
\hline El Molino (EM) & 11 & 2 & 3 & 2 & 4 & 4 & - & 13 \\
\hline Cerro Colorado (CC) & 5 & 3 & 2 & 1 & 3 & 2 & - & 8 \\
\hline Loma de Ichanga (LI) & 2 & - & - & 1 & - & 1 & - & 2 \\
\hline Pueblo Viejo de El Eje (EE) & 3 & - & 2 & 1 & - & - & - & 3 \\
\hline Palo Blanco (PB) & - & 5 & 2 & 2 & 1 & - & - & 5 \\
\hline Loma de los Antiguos (LA) & 22 & - & - & 7 & 11 & 2 & 2 & 22 \\
\hline
\end{tabular}
su eje mayor, considerando 300 puntos de una grilla de 1 $\mathrm{mm}$ de ancho por $0,5 \mathrm{~mm}$ de altura mediante un contador manual.

Tabla 1. Muestra de fragmentos analizados. 


\section{ii) Características y composición de las inclusiones de la fracción de tamaño arena}

Para la caracterización de la fracción de tamaño arena se contaron 100 inclusiones mayores a $62 \mu \mathrm{m}$ (límite granulométrico entre limo y arena muy fina) por corte en una grilla de $1 \times 1 \mathrm{~mm}$ y se siguió el método del punto más cercano (Quinn 2013). Para cada inclusión se determinaron:

a) Composición: se identificaron cristaloclastos, litoclastos, vitroclastos, tiesto molido y minerales opacos. Las inclusiones argiláceas fueron consideradas como matriz. La identificación y caracterización de los componentes se realizó a partir de la consulta bibliográfica (Kerr 1972; Mackenzie y Guilford 1980; Cuomo di Caprio y Vaughan 1993).

b) Tamaño: se midió el eje mayor de las inclusiones (eje a) en escala Udden-Wentworth a través de un ocular graduado. Las categorías reconocidas fueron: arena muy gruesa ( 1 - $2 \mathrm{~mm}$ ), arena gruesa $(0,5-1 \mathrm{~mm})$, arena mediana $(0,25-0,5 \mathrm{~mm})$, arena fina $(0,125-0,25 \mathrm{~mm}) \mathrm{y}$ arena muy fina $(0,062-0,125 \mathrm{~mm})$.

c) Redondez: para el registro se utilizó una adaptación de la carta de Powers (1982). Se utilizaron solo tres categorías: anguloso (reúne granos muy angulosos y angulosos), subanguloso-subredondeado y redondeado (suma inclusiones redondeadas y bien redondeadas).

\section{Análisis estadísticos}

Los componentes de la pasta -matriz, cavidades e inclusiones-, así como las características de las inclusiones -composición, tamaño, redondez- de tamaño granulométrico arena $(0,062-2 \mathrm{~mm})$ se convirtieron en porcentajes. Así, en cada muestra, la suma de las partes es un valor fijo de $100 \%$, una composición en el sentido de Aitchison (1986). Esta estandarización conlleva la dependencia entre los componentes o partes de la composición impuesta por la restricción de la suma constante $(100 \%)$, que imposibilita la utilización de los métodos de análisis estadísticos estándar. Aitchison (1986, 1992, 1999) y Pawlowsky-Glahn y Egozcue $(2001,2002)$, entre otros, formularon un marco teórico que contempla la restricción y propusieron metodologías que consisten en efectuar una serie de transformaciones. Con el objetivo de detectar patrones de agrupamiento entre las piezas se realizaron análisis cluster con el método de Ward para la conformación de los aglomerados (Aitchison, 1992; Aitchison et al. 2000; Alperin et al. 2008), con datos previamente clr transformados (i.e., log-cociente centrada). La muestra y cada uno de los grupos identificados con el análisis cluster se caracterizaron con su centro (media geométrica clausurada) y la varianza total; se definieron como valores anómalos o atípicos a aquellos con índices mayores a 0,95. Los análisis se realizaron con el software CoDaPack v2.02.21 (Comas-Cufí y Thió-Henestrosa 2011) y PAST v2.17 (Hammer et al. 2001).

\section{RESULTADOS DEL ANÁLISIS PETROGRÁFICO}

\section{Características generales de la pasta y de la matriz}

Los resultados de la caracterización general de la pasta se consignan en la Figura 2a. Predominan las orientaciones entre buenas y regulares, pero puede haber muy buenas y malas. En los casos en que las pastas contienen inclusiones grandes (mayores a $0,5 \mathrm{~mm}$ ), frecuentemente la porción de matriz lindante se ordena alrededor de ellas. Las cavidades son mayormente irregulares, mientras que las grietas y las de tipo mixto se encuentran en una frecuencia importante.

La matriz característica es entre arcillo-limosa y limo-arcillosa, con cantidades variables de micas de tamaños muy pequeños y minerales félsicos, mayormente de tamaño limo grueso. También se observan pequeños fragmentos pumíceos y trizas vítreas -cuando están presentes en proporciones abundantes entre las inclusiones tamaño arena-, gránulos de arcilla y minerales opacos. Las micas, preferentemente biotita, suelen ser predominantes sobre el resto de los materiales tamaño limo, y generalmente varían en cuanto a su densidad de una pared de la vasija a la otra (Figura 3).

\section{Porcentajes matriz - cavidades - inclusiones $(\mathrm{MCl})$}

La composición promedio (centro) de los porcentajes de $\mathrm{MCl}$ es $77 \%$ de matriz, $19 \%$ de inclusiones y $4 \%$ de cavidades, y se observa que las componentes poseen baja variabilidad total (Var. clr total $=0,53)$. Las variabilidades de la matriz y de las inclusiones son similares (Var. clr $\approx$ $0,15)$ y menores que las de las cavidades (Var. $c l r=0,24)$. Se detectaron tres piezas anómalas: la olla LEV5.24 $(\mathrm{MCl}=94,1,5 \%)$ y las tinajas CC7.12 $(\mathrm{MCl}=88,4,8 \%)$ y CC7.13 $(\mathrm{MCl}=89$, 5, 6\%) (Figura 2b). 
a

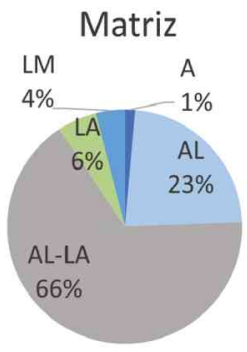

Orientación

muy buena

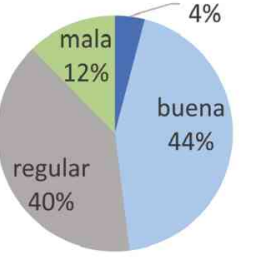

Cavidades

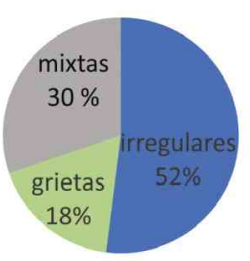

Principales tipos de limos

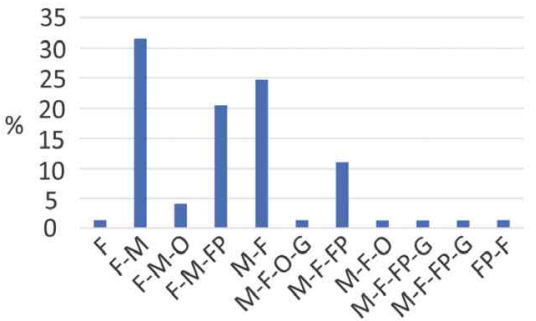

Matriz

b
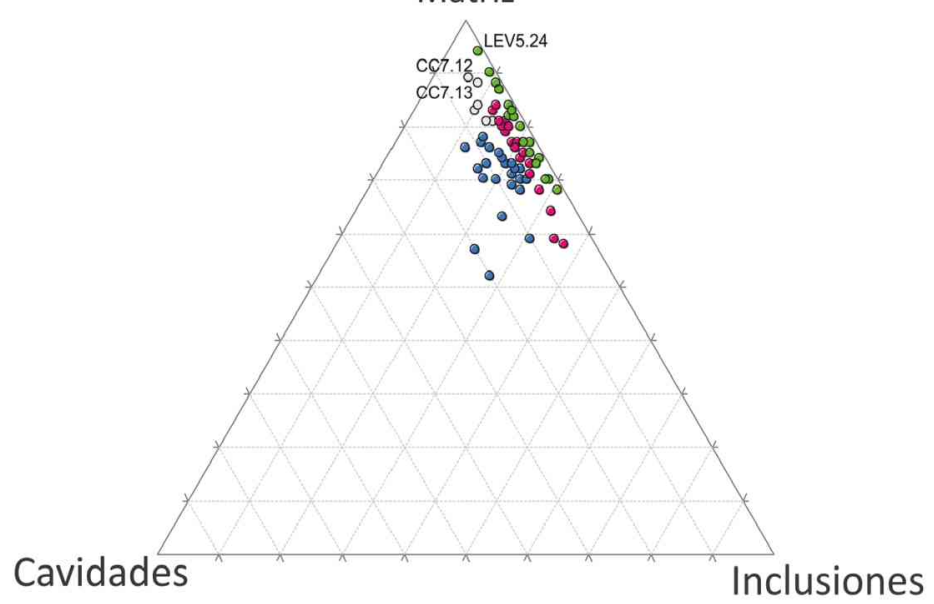

$\begin{array}{lll}\mathrm{A} 1 & \mathrm{~A} 2 & \mathrm{~B} 1\end{array}$

1 B2

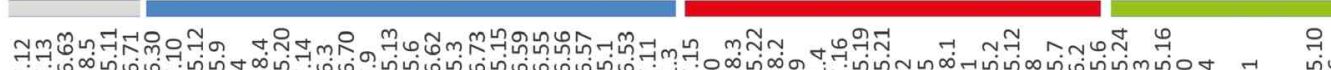

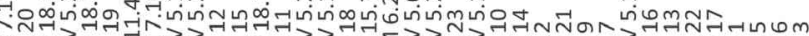

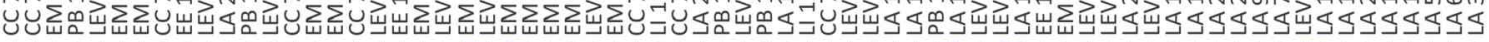

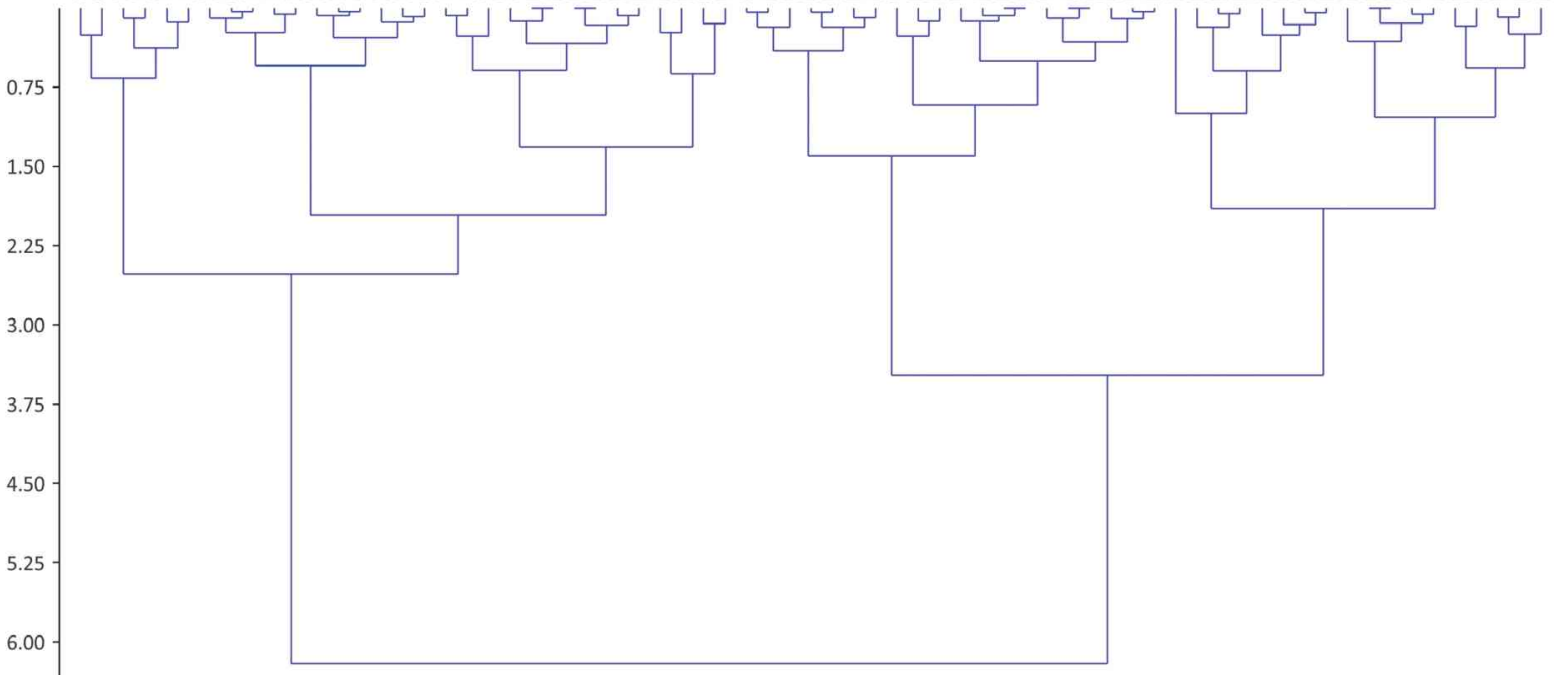

6.75

C

Referencias: a) Diagrama de tortas de la composición granulométrica de la matriz, de la orientación y del tipo de cavidades de las pastas, y diagrama de barras de la composición litológica de los limos. A: matriz arcillosa, AL: matriz arcillo-limosa, AL-LA: matriz entre arcillo limosa y limo-arcillosa, LA: matriz limo-arcillosa, LM: matriz limosa-micácea; entre los limos predominan las micas y la fracción arcillosa no es claramente visible. F: minerales félsicos (cuarzo + feldespatos), M: micas, O: minerales opacos, FP: fragmentos pumíceos, G: gránulos de arcilla. b) Triángulo composicional de $\mathrm{MCl}$. c) Dendrograma obtenido usando los datos de $\mathrm{MCl}$ c/r-transformados, método Ward y la distancia euclidiana.

Figura 2. Características generales de la pasta 

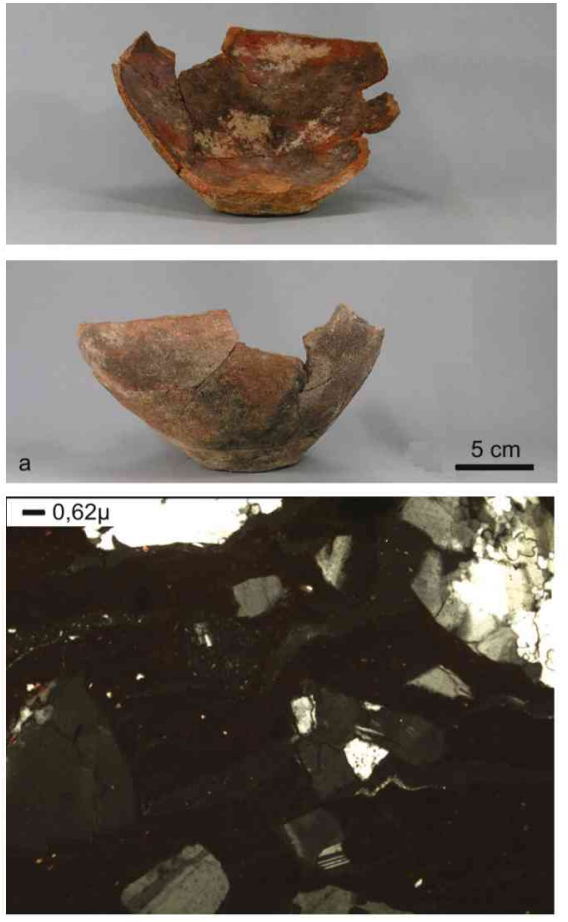

$2 \mathrm{~cm}$
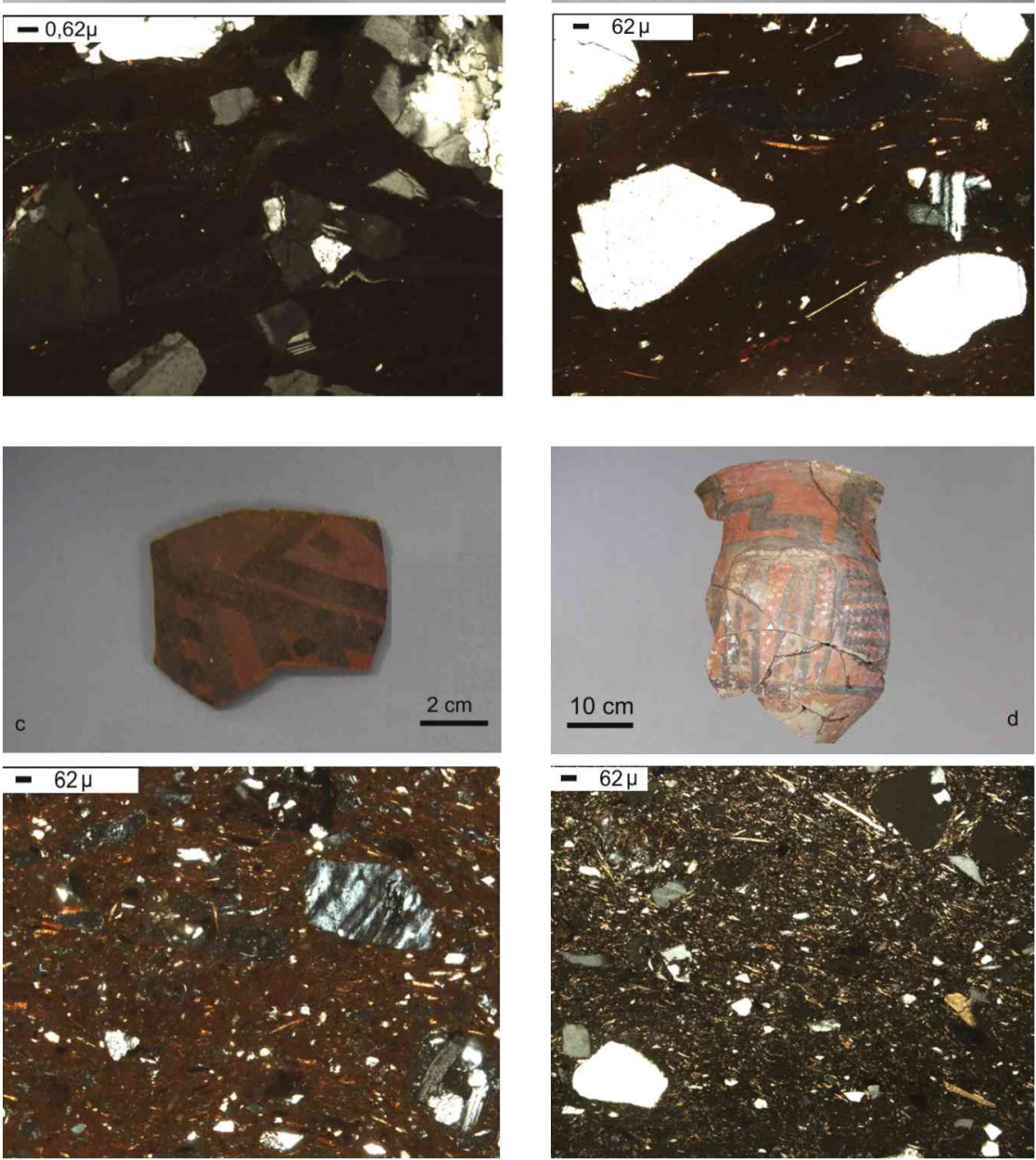

Referencias: a) Puco Belén (LI11.3) con matriz arcillosa; b) fragmento de tinaja Belén (EM6.57) con matriz arcillo-limosa; c) fragmento de tinaja Belén (EM6.63) con matriz entre arcillo-limosa y limo-arcillosa; d) tinaja (LA14) con matriz limo-arcillosa. Fotomicrografías tomadas con luz polarizada cruzada a $100 x$

Figura 3. Aspecto de la matriz de la cerámica Belén bajo microscopio petrográfico, según cantidad de limo y arcilla.

La Figura 2c muestra el dendrograma resultado del análisis cluster. Se diferencian dos grupos a una distancia de similitud de 6,62: A y B. Ambos se separan debido al porcentaje de cavidades que poseen, que es mayor en el grupo A. El grupo A, a su vez, se subdivide en $\mathrm{A} 1$ y $\mathrm{A} 2$ a 2,4 unidades de similitud. El grupo A1 reúne seis piezas que tienen el centro $\mathrm{MCl}=84,73 ; 5,44 ; 9,38 \%$; y el A2 junta 25 cortes con centro $\mathrm{MCl}=71,09$; 8,$80 ; 20,11 \%$; la principal diferencia se encuentra en el porcentaje relativo de inclusiones. El grupo $B$ se separa en $B 1$ y $B 2$ a 0,38 unidades. B1 agrupa 20 piezas cuyo centro es $\mathrm{MCl}=74,97$; 3,$79 ; 21,24 \%$; y B2 está integrado por 18 cortes con centro $\mathrm{MCl}=80,75$; 1,$34 ; 17,92 \%$. En los grupos $A 1, A 2$ y $B 1$ no se observa ninguna correspondencia con los sitios donde fueron obtenidos los fragmentos, ni con la forma cerámica, ni con el sector del cuerpo; el grupo B2, notablemente, está integrado por una importante cantidad de cortes de Loma de los Antiguos, similares especialmente por la baja cantidad de cavidades.

\section{Características de las inclusiones con granulometría arena $(0,062-2 \mathrm{~mm})$}

Los componentes de las pastas han sido descritos previamente, y en su mayor parte corresponden a sedimentos arenosos (Wynveldt 2009; Zagorodny et al. 2010; lucci 2016). Entre los cristaloclastos se distinguieron cuarzo -generalmente, de extinción recta-, feldespatos calcosódicos (plagioclasas) y potásicos, micas -biotita, la más abundante, y muscovita-, anfíboles, generalmente en su variedad hornblenda, y minerales de hierro. Entre los litoclastos se reconocieron fragmentos líticos de origen plutónico, volcánico, metamórfico y sedimentario. Se observan regularmente fragmentos pumíceos y solo en casos puntuales se encuentra tiesto molido. 
Para una primera subdivisión, se tomó en consideración la presencia y proporción de fragmentos pumíceos y tiesto molido. En el primer caso, dado que su proporción se diferencia notablemente del conjunto de la muestra; y en el segundo, en función de que se considera como un componente añadido intencionalmente. De este modo, la muestra se subdividió en tres grandes grupos (Figura 4):

- Grupo 1: presenta tiesto molido. Está integrado por seis piezas del sitio El Molino. Corresponden a un puco y dos tinajas que presentan las características comunes del tipo cerámico Belén, y otras tres que pueden incluirse dentro de un grupo de tinajas que no presentan todos los elementos estructurales de la morfología, gestos de manufactura e imágenes tal como han sido definidos para esta cerámica (Wynveldt 2009). En uno de los cortes (tinaja EM6.59), el tiesto molido conforma más del $50 \%$ de las inclusiones; pertenece a la única pasta con matriz limosamicácea, extraída de un fragmento que tiene diferencias de coloración con respecto a otras vasijas Belén, tanto en superficie como en fractura fresca, y su pasta es algo más friable. Los otros cortes (puco EM6.55, tinaja EM6.56, tinaja EM6.63, tinaja EM6.73) tienen entre 16 y $44 \%$ de tiesto molido entre sus inclusiones, $y$ el resto de los elementos son las arenas regulares para este tipo de cerámica.

- Grupo 2: presenta un marcado predominio de fragmentos pumíceos. Está formado por dos tinajas (LEV5.19 y LEV5.21) y un puco (EM6.53) en los que se hallaron altos porcentajes de un componente de origen piroclástico. Este componente alcanza valores de 84, 77 y $63 \%$ de fragmentos pumíceos respectivamente; además, presenta inclusiones de plagioclasa, cuarzo - anfíbol con rebordes de pasta vítrea. La plagioclasa, cuarzo y anfíbol aislados en la pasta probablemente formen parte del mismo sedimento piroclástico $y$, por lo tanto, la cantidad de material de este origen es aún mayor.

- Grupo 3: conforma el grupo más numeroso de la muestra (59 cortes), en el que las inclusiones son sedimentos arenosos con algunas variaciones en cuanto a la proporción de cada uno de sus componentes. La composición de las inclusiones tiene su centro caracteri-

a. EM6.56

LEVsup cruzada.
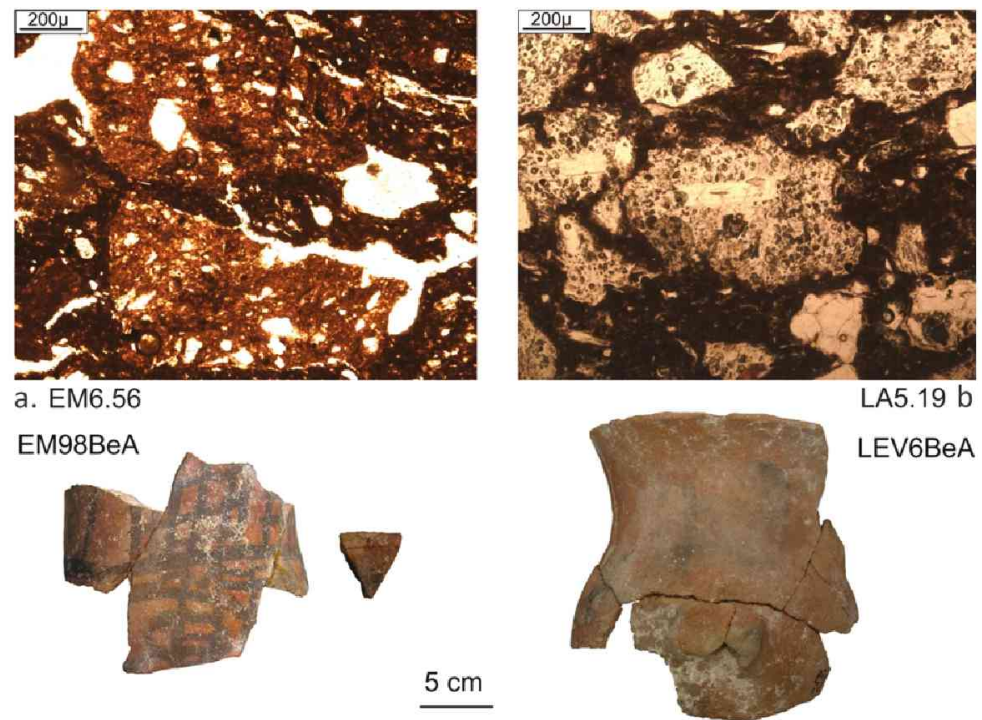

zado por fragmentos pumíceos $=26,03 \%$; cuarzo tos plutónicos $=6,04 \%$; litoclastos volcánicos $=$ $4,96 \%$, litoclastos metamórficos $=4,96 \%$ y otros (biotitas, anfíboles, opacos, litoclastos sedimentarios) $=6,31 \%$. Los componentes más variables son los litoclastos metamórficos, los volcánicos y los plutónicos (Var. clr $\approx 0,36$ ); los demás son levemente menos variables (Var. clr $\approx 0,25)$. La variabilidad total de la muestra es grande (Var. clr total $=21$ ). Se identificaron ocho cortes con composiciones anómalas, principalmente en los porcentajes de litoclastos metamórficos y volcánicos, en las tinajas LA2, LA6, LA12 y EE15.7, los pucos LA24, LI11.3, CC7.11 y LEV5.20 y la olla LEV5.24.

$5 \mathrm{~cm}$

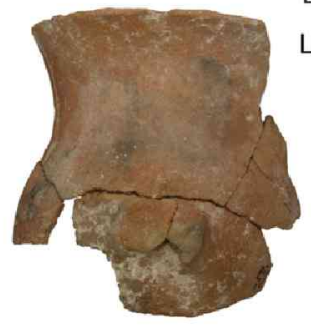

L5.19 b

LEV6BeA
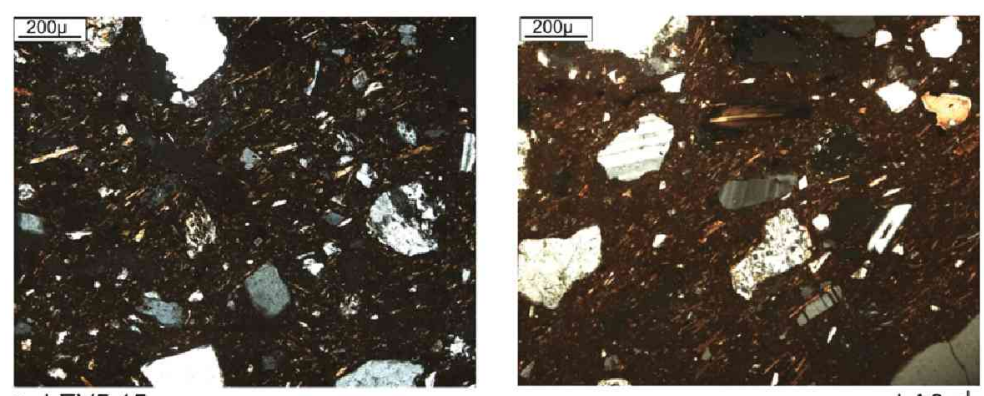

LA8 d.

LABe8A
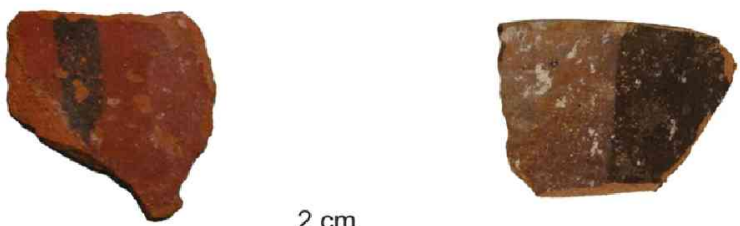

$2 \mathrm{~cm}$

Referencias: a) Grupo 1, con tiesto molido; b) Grupo 2, con predominio de fragmentos pumíceos; c) y d) Grupo 3, con sedimentos arenosos. Fotomicrografías tomadas a 100x, a y b con luz paralela, c y d con luz polarizada

Figura 4. Grupos de pastas de la cerámica Belén. 
La Figura 5a es el dendrograma resultado del Análisis cluster del grupo 3, luego de retirar una muestra que se separaba significativamente del conjunto, LEV5.24, por la virtual ausencia de litoclastos.
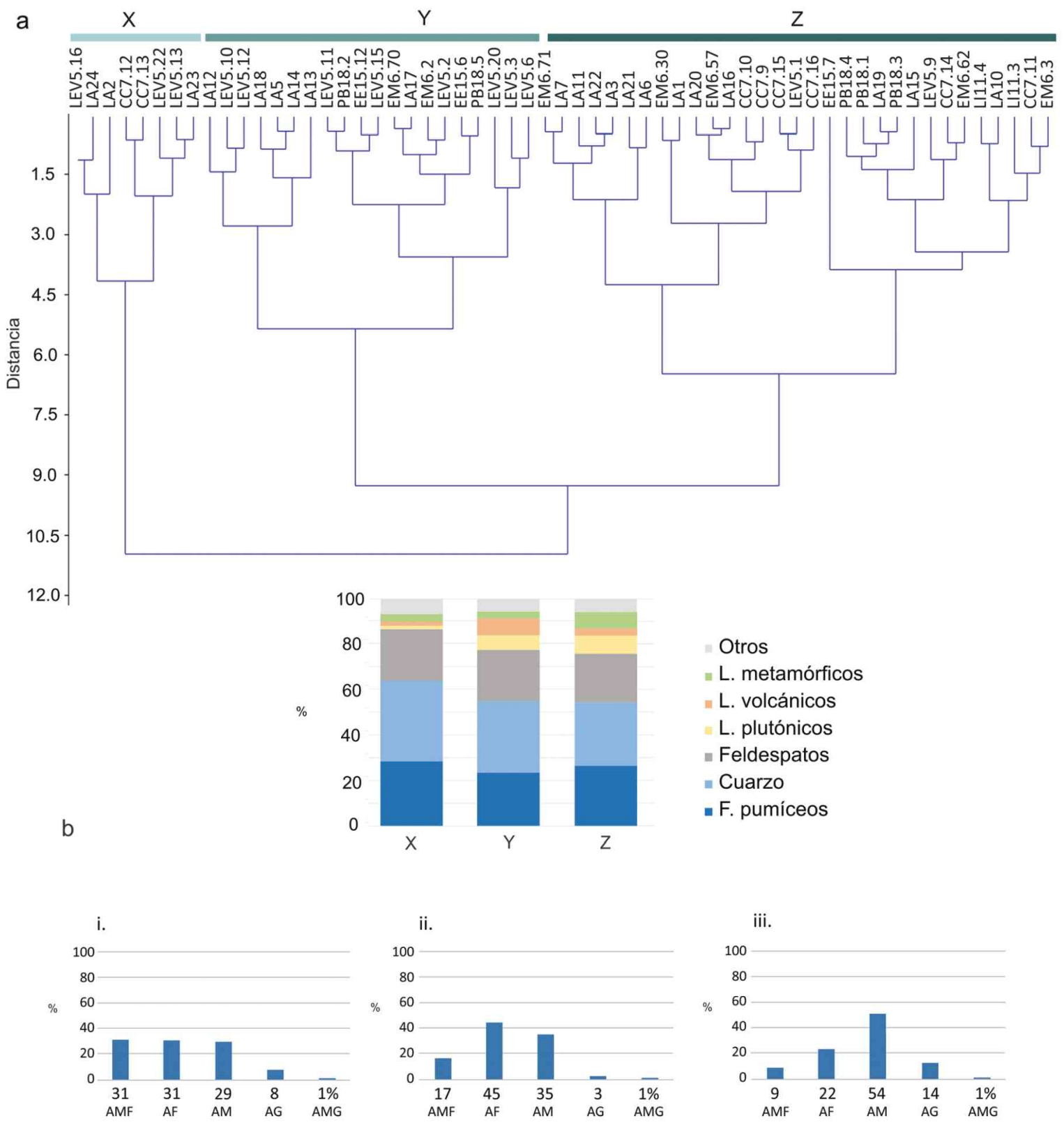

iii.
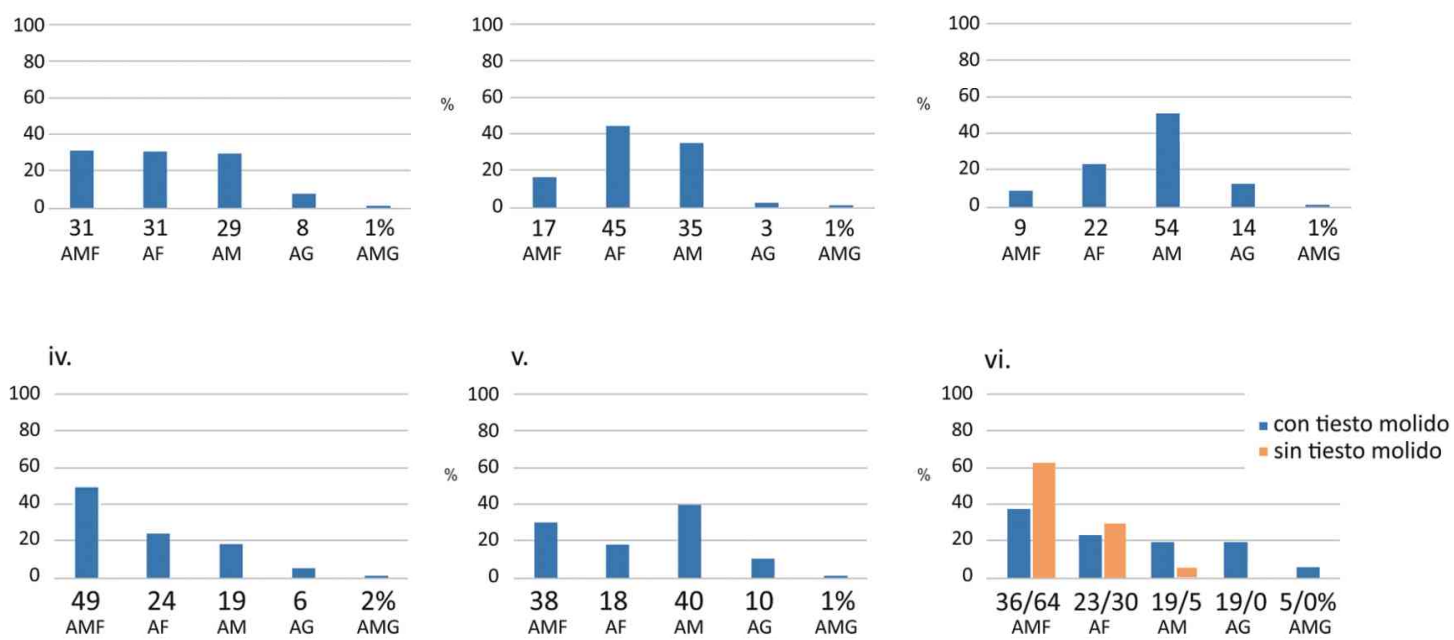

C

Referencias: a) Dendrograma obtenido con los datos clr-transformados de la composición de las inclusiones tamaño arena, efectuado con el método de agrupamiento Ward y la distancia euclidiana; b) Gráficos de barra que muestran la composición promedio (centro) de cada uno de los grupos identificados en el dendrograma; c) Gráficos de las distribuciones promedio de los grupos de tamaño: i) cantidades uniformes en los distintos rangos de tamaño, ii) predominio de arenas finas y medianas, iii) moda de arena mediana, iv) moda de arena muy fina, v) distribuciones bimodales, vi) corte EM6.56, con y sin tiesto molido.

Figura 5. Gráficos de composición y tamaño del grupo de pastas con predominio de inclusiones de sedimentos de fracción granulométrica arena. 
En él se diferencian tres grupos, el grupo $X$ se separa del grupo $Y-Z$ a 11,3 unidades de distancia; en tanto el grupo $Y$ se separa del $Z$ a la distancia de similitud 9,4. El grupo $X$ reúne ocho piezas; el $Y, 20$; y el $Z, 31$. Las principales diferencias se encuentran en los contenidos de cuarzo y de litoclastos volcánicos, plutónicos y metamórficos (Figura 5b).

Para la evaluación de la granulometría de las inclusiones de tamaño arena se tomó el conjunto de la muestra con la exclusión de los cortes que contienen tiesto molido. La granulometría promedio (centro) es: arena muy fina $\mathrm{AMF}=25 \%$, arena fina $\mathrm{AF}=30 \%$, arena mediana $\mathrm{AM}=36 \%$, arena gruesa $\mathrm{AG}=8 \%$ y arena muy gruesa $\mathrm{AMG}=1 \%$; la muestra es muy variable (var. total $45,22 \%$ ) y tiene un claro predominio de las tres fracciones más finas. Los principales tipos de distribución de tamaño presentes son: i) cortes con cantidades relativamente uniformes en los distintos rangos de tamaño, con modas en arena fina y/o mediana moderadamente marcadas, representado por 13 casos; ii) con predominio de los tamaños arena fina y mediana, 15 casos; iii) con moda bien marcada en arena mediana, 13 casos; iv) con modas de arena muy fina $y$ desarrollo de una cola de arenas más gruesas, 10 casos; y v) distribuciones bimodales con diferente grado de demarcación respecto de sus modas, 10 casos (Figura $5 \mathrm{c}$ ). Se observaron siete casos raros: las ollas LEV5.24 y LA23 tienen moda en arena muy fina y no presentan cantidades importantes de arena mediana, y el puco CC7.10 tiene una moda de arena gruesa. El puco EM6.53 -que se encuentra entre los casos con porcentajes altos de fragmentos pumíceos- se agrupó junto con las muestras bimodales, pero es un caso peculiar dado que su moda principal presenta el tamaño arena gruesa. El puco CC7.11 tiene una moda muy marcada en el tamaño arena mediana; la tinaja CC7.12 presenta una distribución de AMF, AF y AM diferente al resto de los casos; y por último, la tinaja LA17 posee una moda muy marcada en arena fina.

Por otra parte, en los cortes con tiesto molido se observa un patrón bimodal, en el que a un contenido de sedimento de tamaño arena muy fina y fina se le suma un contenido de tiesto molido de tamaño arena mediana y gruesa (Figura $5 \mathrm{c}$, vi).

En relación con el redondeamiento, dado que el punto de interés se encuentra en la evaluación de la elección técnica o de las características del ambiente de procedencia de los sedimentos para confeccionar la pieza, no se consideraron los cortes con tiesto molido. La composición de la muestra tiene promedio (centro) $=$ angulosos $=9 \%$, subangulosos-subredondeados $=78 \%$ y redondeados $=13 \%$, con varianzas $=0,34,0,11$ y 0,35 respectivamente. La preeminencia de inclusiones subangulosas-subredondeadas es clara, y dentro de este grupo dominan las subangulosas. Los individuos redondeados se presentan en cantidades menores al $10 \%$ en 14 cortes, en cantidades superiores a $20 \%$ se encuentran en nueve, y 36 cortes tienen entre un 11 y $20 \%$ de inclusiones fracción arena bien redondeada. Entre los casos atípicos se encuentran la tinaja LEV5.19, con predominio de fragmentos pumíceos angulosos (38\%); la tinaja LEV5.9, con una virtual ausencia de clastos angulosos; y la olla LEV5.24, en la que no se registraron inclusiones redondeadas. Las tinajas LEV5.20 y EM6.30 constituyen los únicos casos en que dominan las inclusiones redondeadas ( $34 \%$ y $42 \%$, respectivamente).

\section{DISCUSIÓN}

Los resultados obtenidos en la observación de las variables de matriz, tipo de orientación y forma de cavidades indican que, si bien el conjunto presenta una diversidad de atributos, las opciones de manufactura utilizadas recaen mayormente en solo una o dos variantes. Las pastas son preferentemente arcillo-limosas y limo-arcillosas. La fracción limo generalmente está formada por micas y minerales félsicos, también puede contener otros materiales si se encuentran en abundancia en el tamaño arena, como por ejemplo fragmentos pumíceos. El tipo de orientación se relaciona con las modalidades de preparación de la mezcla, amasado y modelado de la pieza (Rye 1981). En la muestra, la orientación es preferentemente buena y puede vincularse con el rodeteado de la arcilla. La orientación de tipo regular se observa en una importante cantidad de casos, y puede ser explicada por diversos factores que inciden en la disposición de los elementos de la pasta, como las modalidades de aplastamiento de los rollos y el acomodamiento de la arcilla durante el levantado de la pieza, y la realización del corte en los sectores de unión de rollos o segmentos.

La distribución de la matriz, cavidades e inclusiones muestra una baja variabilidad total, que indica el mantenimiento de proporciones generales en la combinación de los distintos componentes. Los cuatro grupos identificados (A1, A2, B1 y B2, 
Figura 2c) expresan las principales proporciones de materiales que se utilizaban, más allá de sus características de composición y textura específicas, y la existencia de regularidades en el proceso de preparado de la pasta. Su dispersión puede asociarse a que las recetas que se seguían no eran estrictas ni estandarizadas. Entre los grupos obtenidos no se hallaron correspondencias con los sitios, forma o sector de la vasija. La tendencia más interesante para destacar es la concentración de muestras de Loma de los Antiguos, causada por la escasa cantidad de cavidades, que posiblemente se relacione con prácticas comunes de preparación de la pasta, amasado o cocción de las piezas. Considerada juntamente con la mayor uniformidad morfométrica y de las imágenes de la alfarería de la zona (Wynveldt 2009; lucci 2016), esta observación cobra relevancia dado que podría vincularse con una tradición local de manufactura por parte de ceramistas relacionados estrechamente entre sí.

Con relación a la composición de las inclusiones de tamaño arena, se destacan tres agrupamientos principales. El grupo 1 se determinó por la presencia de tiesto molido, un componente atípico en las pastas Belén y propio de la cerámica ordinaria (Zagorodny et al. 2010; Puente 2012; lucci 2016), que se asocia a la Belén en todos los contextos pero que probablemente se manufacturaba en esferas de producción diferentes (lucci 2016). También es un añadido característico de la alfarería Santa María, que se distribuye en el área de Yocavil, contigua al Valle de Hualfín, y zonas aledañas; y de las urnas negro sobre rojo tardías del área de Yocavil, que comparten elementos propios de la alfarería Belén y Santa María (Palamarczuk et al. 2014). De la muestra analizada, los cortes con tiesto molido se limitan a El Molino, un sitio del sector norte del valle en el que se registran proporciones altas de cerámica Santa María y cuya materialidad es indicativa de fuertes vínculos con las poblaciones de la región de Yocavil (lucci 2016). De este modo, es posible plantear que la presencia de este componente en la cerámica Belén se relacione más con una práctica producto de la interacción entre los grupos de las áreas de Hualfín y Yocavil, que con la tecnología de producción de la cerámica ordinaria.

El grupo 2 se caracteriza por el predominio de fragmentos pumíceos, un elemento común en toda la muestra examinada, pero que en este caso conforma prácticamente el único tipo de inclusión. En el valle de El Bolsón se han observado fragmentos cerámicos de este tipo, igualmente reducidos en cantidad de ejemplares (Puente 2012). Para áreas cercanas como Tafí del Valle, se propone que el uso sistemático de fragmentos pumíceos como atemperante se vincula con un cambio en la producción cerámica vinculada con la llegada de los inkas (Páez y Sardi 2014), y casos de similares características se registran en diferentes zonas de Argentina, entre ellas, en el sitio El Shincal (Cremonte et al. 2015), en diversos sitios de la provincia de Mendoza (Prieto Olavarría y Páez 2015) y en Paria, Bolivia (Sziláyi y Szakmány 2009). La cerámica de filiación inkaica, al igual que otros tipos de evidencias materiales de la presencia imperial, está ausente o se encuentra en muy baja frecuencia de aparición en los sitios locales del Valle de Hualfín. Si se asume la asociación entre esta modalidad de añadido de inclusiones y la presencia inkaica (Páez y Sardi 2014; Prieto Olavarría y Páez 2015), la muy escasa frecuencia de hallazgos de este tipo en el valle lleva a considerar la hipótesis de la incidencia del Estado en la producción cerámica local solo como casos aislados y no como una política desplegada para el área.

El grupo más numeroso (grupo 3) está constituido por pastas que presentan sedimentos arenosos que se comportan de manera coherente con las arenas del área (Muruaga 2001; lucci 2013; Delaloye et al. 2016) y con otros conjuntos de cerámica Belén estudiados previamente (Zagorodny et al. 2010; Puente 2012). A partir del análisis de cluster, se lo subdividió en otros tres ( $X, Y Z$ ), cuyas diferencias se encuentran en las proporciones de cuarzo y de los distintos tipos de litoclastos que no se correlacionan con los sitios, las formas o los sectores del cuerpo cerámico. El alto grado de variabilidad indicaría que la fracción arena utilizada en la pasta puede proceder de diversos sectores de aprovisionamiento de diferente composición o bien de áreas acotadas en el espacio diferenciadas internamente, dado que los depósitos arenosos de los cauces de los ríos presentan variaciones en proporción, características y madurez textural de los elementos componentes, que pueden ocasionar que de un área restringida sea posible obtener sedimentos diferentes.

En el caso de la distribución de tamaños de este grupo, uno de los puntos destacables es la escasa presencia de tamaños gruesos. En términos de prácticas de manufactura implica, o bien la selección de sedimentos de rangos de tamaño pautados, o bien el tamizado. También indica una marcada distinción de los tipos de inclusiones que se utilizaron 
para la manufactura de la cerámica ordinaria, diferente no solo en composición sino en cuanto al tamaño de las inclusiones, que son distintivamente más gruesas (lucci 2016). Los casos de distribución de tamaño bimodal pueden ser considerados como clara evidencia de agregado de atemperantes (Velde y Druc 1999; Quinn 2013). Por otra parte, el predominio de niveles de redondeamiento intermedios (subangulosos y subredondeados) se diferencia de los sedimentos observados en diferentes puntos de muestreo de ríos (Delaloye et al. 2016; lucci 2016), que en su conjunto muestran mayor proporción de clastos redondeados. Esta falta de correspondencia puede asociarse con diferentes causas, como por ejemplo, con una divergencia entre los puntos de muestreo de los sedimentos con aquellos efectivamente usados por los alfareros, con la mezcla de sedimentos de diverso origen en la manufactura, respecto de lo cual las arenas con buen redondeamiento podrían haber sido solo uno de los componentes usados, o con el uso de arenas de procedencias diferentes a las de origen fluviales, como por ejemplo las eólicas, que es un tipo de material expuesto en distintos puntos del valle.

La conjugación de las diferentes variables analizadas para el grupo mayoritario permite plantear algunas alternativas para la preparación de la pasta (lucci 2016), entre las que se destacan dos opciones. La primera es el uso de arcillas con una cantidad importante de limo, a la que podrían añadirse sedimentos entre muy finos y medios; y la segunda, el uso de arcillas con sedimentos de tamaño limo y arena muy fina, con la incorporación de sedimentos con alta proporción de clastos redondeados de tamaños finos y medios.

En todas las variables registradas se encuentran casos estadísticamente atípicos. Estos son relevantes porque evidencian elecciones en el transcurso de la manufactura que se diferencian de las modalidades más comunes. Entre ellos, pueden mencionarse como ejemplo el uso de arcillas sin limos, fuentes de arenas de composición y/o textura distintiva, o variaciones en las modalidades de amasado y rodeteado de la arcilla.

En síntesis, la alfarería Belén tiene atributos generales que son identificatorios del tipo de cerámica y que pueden ser interpretados como producidos por prácticas con ciertas regularidades para la preparación de la pasta, el amasado, las distintas etapas del levantado y cocción de las piezas. Sin embargo, estas características generales no eximen al conjunto de cierta variabilidad en uno o más atributos, observable en vasijas numéricamente minoritarias y que pueden considerarse casos excepcionales, o en las que se manifiesta la incidencia de factores relacionados con la interacción entre diferentes poblaciones productoras.

\section{CONCLUSIONES}

Una primera observación de la cerámica Belén bajo microscopio petrográfico puede conducir a detectar una importante variabilidad en las características de las pastas. No obstante, el abordaje a partir del uso de datos semicuantitativos y cuantitativos y la estadística de datos composicionales permite la identificación de regularidades en la manufactura cerámica que tienen incidencia en el estudio de las prácticas tecnológicas y de la organización de la producción.

El análisis de las pastas muestra que, para su preparación, en líneas generales, se respetaban proporciones de materiales, tipos de materias primas y características texturales de las arenas. La diferenciación de las cantidades y los tamaños de los diversos componentes no puede correlacionarse con los tipos de piezas, de formas o con procedencias de lugares específicos, y puede vincularse a la variabilidad interna de los depósitos de donde se habrían obtenido las materias primas, así como al uso de diferentes depósitos.

En este sentido, las modalidades de preparación de pastas y manufactura siguen una misma lógica práctica: el agregado de inclusiones, sedimentos arenosos $y$, eventualmente, fragmentos pumíceos en baja cantidad. Probablemente, también se utilizaran de modo repetido los mismos lugares para la extracción de recursos, y esto no necesariamente redundaba en pastas estandarizadas, dadas ciertas diferencias intrínsecas a los depósitos arenosos. De este modo, la variabilidad puede considerase como la manifestación de una práctica tecnológica común con diferencias vinculadas a las fluctuaciones de los sedimentos en la escala del valle $y$, posiblemente, a la elección de sedimentos de características de color y textura particulares por parte de los alfareros.

Al igual que en el caso de las variables morfométricas y de las imágenes de la alfarería Belén, el estudio de las pastas permite plantear condiciones de producción estructuradas, con elaboración de series de piezas relativamente uniformes, pero también con lugar para la experimentación y la prueba de 
materiales que ocasionaban la elaboración de algunas piezas algo diferentes. La presencia geográficamente localizada de fragmentos con tiesto molido, así como de pastas con añadidos de altas proporciones de fragmentos pumíceos en casos minoritarios, conducen a evaluar como posibilidad algunos cambios en las prácticas de producción alfareras vinculadas con las interacciones entre poblaciones en la escala regional y con el Estado inkaico.

\section{Agradecimientos}

Este trabajo se realizó en el marco de proyectos financiados por la Agencia Nacional de Promoción Científica y Tecnológica y la Universidad Nacional de La Plata. Los Lics. M. Morosi y N. Zagorodny participaron en distintas instancias de la observación e interpretación de los resultados. Los evaluadores anónimos contribuyeron a darle claridad al manuscrito. No obstante, todo lo expuesto aquí es de exclusiva responsabilidad de las autoras.

\section{REFERENCIAS CITADAS}

Aitchison, J.

1986 The statistical analysis of compositional data. Monographs on Statistics and applied Probability. Chapman and Hall, Londres.

1992 On criteria for measures of compositional difference. Mathematical Geology 24: 365-379. 1999 Logratios and natural laws in compositional data analysis. Mathematical Ceology 131: 563-580.

Aitchison, J., C. Barceló-Vidal, J. A. Martín-Fernández y V. Pawlowsky-Glahn

2000 Logratio analysis and compositional distance. Mathematical Ceology 32: 563-580.

Alperin, M., E. Bernasconi y G. Cusminsky

2008 Asociaciones de foraminíferos bentónicos recientes de la Plataforma Continental Argentina $\left(39^{\circ}-43^{\circ} \mathrm{S}\right.$ y $\left.58^{\circ}-65^{\circ} \mathrm{O}\right)$ analizados con métodos estadísticos para datos composicionales. Ameghiniana 45 (2): 443-461.

Arnold, D.

2000 Does the Standarization of Ceramic Pastes Really Mean Specialization? Journal of Archaeological Method and Theory 7 (4): 333-375.

Balesta, B., N. Zagorodny y F. Wynveldt

2011 La configuración del paisaje Belén (Valle de Hualfín, Catamarca). Relaciones de la Sociedad Argentina de Antropología XXXVI: 149-175.
Basile, $M$.

2009 Recorriendo trazos. Un aporte a la definición del estilo decorativo Belén. Arqueología 15: 13-40.

Blackman, M., G. Stein y P. Vandiver

1993 The standardization hypothesis and ceramics mass production: technological, compositional, and metric indexes of craft specialization at Tell Leilan, Syria. American Antiquity 58 (1): 60-80.

Bossi, G. E. y C. M. Muruaga

2009 Estratigrafía e inversión tectónica del 'rift' neógeno en el Campo del Arenal, Catamarca, NO Argentina. Andean Geology 36 (2): 311-341.

Comas-Cufí M. y S. Thió-Henestrosa S. 2011 CoDaPack 2.0 Universitat de Girona. http://ima. udg.edu/codapack/

Costin, C. $y$ M. Hagstrum 1995 Standardization, labor investment, skill, and the organization of ceramic production in late prehispanic Peru. American Antiquity 60: 619-639.

Cremonte, M. B., G. Maro y A. M. Díaz

2015 Acercamiento a la producción y distribución del estilo Inca Pacajes. Un estudio arqueométrico de las pastas. Chungara, Revista de Antropología Chilena 47 (3): $387-400$.

Cuomo di Caprio, N. y S. Vaughan 1993 An experimental study in distinguishing grog (chamotte) from argillaceous inclusions in ceramic thin sections. Archaeomaterials 7: 21-40.

De La Fuente, G. A.

2011 Urns, bowls and ollas. Pottery making practices and technical identity in the Southern Andes during the Late Period (Ca. 900-1450) (Catamarca, Northwestern Region, Argentina). Latin American Antiquity 22 (2): 224-252.

De La Fuente, G. A., J. R. Ferguson y M. D. Glascock 2015 Chemical and petrographic analysis of pre-hispanic pottery from the southern Abaucán Valley, Catamarca, Argentina. Archaeometry 57 (1): 1-17.

Delaloye, H., M. E. lucci y M. L. Delgado 2016 Caracterización composicional y textural de arenas del río Belén (prov. de Catamarca): aporte para el estudio de sedimentos potenciales para la manufactura de la alfarería tardía. Actas del XIX Congreso Nacional de Arqueología Argentina: 1405-1411. San Miguel de Tucumán.

Dietler, M. y I. Herbich

1998 Habitus, techniques, style: an integrated approach to the social understanding of material culture and boundaries. En The archaeology of social boundaries, editado por M. Stark, pp. 232-263. Smithsonian Institution Press, Washington. 
Freestone, I. C.

1991 Extending ceramic petrology. En Recent developments in ceramic petrology, editado por A. P. Middleton y I. C. Freestone, pp. 399-410. Occasional Paper 81, British Museum Press, Londres.

Hammer, $\varnothing .$, D. A. T. Harper y P. D. Ryan

2001 PAST: Paleontological Statistics Software Package for Education and Data Analysis.

lucci, M. E.

2013 Análisis textural de la fracción arena en cortes delgados de cerámica Belén (Puerta de Corral Quemado, Catamarca). En Arqueometría argentina: estudios pluridisciplinarios, editado por M. Ramos, M. Lanza, V. Helfer, V. Pernicone, F. Bognanni, C. Landa, V. Aldazabal y M. Fernández, pp. 175-193. Aspha y Programa de Arqueología Histórica y Estudios Pluridisciplinarios, Departamento de Ciencias Sociales, Universidad Nacional de Luján, Luján.

2016 Producción, uso y circulación de cerámica tardia en el Valle de Hualfín (Catamarca, Argentina). Sociedad Argentina de Antropología, Buenos Aires.

Johnson, M. R.

1994 Thin section grain size analysis revisited. Sedimentology 41: 985-999.

Kerr, P.

1972 Mineralogía óptica. Ediciones del Castillo, Madrid.

Longacre, W.

1999 Standardization and specialization: what's the link? En Pottery and people, editado por J. Skibo y G. Feinman, pp. 44-58. University of Utah Press, Salt Lake City.

Lynch, J.

2011 La construcción del paisaje y la organización del espacio en el sector norte del Valle de Hualfín (Pcia. de Catamarca). Tesis Doctoral inédita. Facultad de Ciencias Naturales y Museo, Universidad Nacional de La Plata, La Plata.

MacKenzie, W. F. y C. Guilford 1980 Atlas of rock forming minerals in thin sections. Longman, Londres.

Middleton, A. P., I. C. Freestone y M. N. Leese 1985 Textural analysis of ceramic thin sections: evaluation of grain samples procedures. Archaeometry 27 (1): 64-74.

Muruaga, C. M.

2001 Petrografía y procedencia de areniscas terciarias en la Subcuenca de Hualfín, provincia de Catamarca, noroeste de Argentina. Revista de la Asociación Argentina de Sedimentología 8 (2): 15-35.
Páez M. C. y M. L. Sardi

2014 Changes in pottery production under Inca rule in a frontier site in the Tafí Valley, Argentina: a mineralogical analysis. Nawpa Pacha, Journal of Andean Archaeology 34 (1): 61-78.

Palamarczuk, V., A. Reynoso y M. Marchegiani 2014 Estudio sobre las pastas de urnas negro sobre rojo tardías de Yocavil (pcia. de Catamarca, Noroeste argentino). Una primera aproximación. Comechingonia. Revista de Arqueología: 18 (1): 161-168.

Pawlowsky-Glahn, V. y J. J. Egozcue 2001 Geometric approach to statistical analysis on the simplex. Stochastic Environmental Research and Risk Assessment 15: 384-398.

2002 BLU estimators and compositional data. Mathematical Geology 34: 259-274.

Powers, M.

1982 A new roundness scale for sedimentary particles. Journal of Sedimentary Petrology 23: 117-119.

Prieto Olavarría, C. y M. C. Páez

2015 Presencia de inclusiones piroclásticas en la cerámica de los siglos XV a XVII en el Centro Oeste y Noroeste Argentino. Chungara, Revista de Antropología Chilena 47 (3): 441-454.

Puente, V.

2012 Lo que "oculta" el estilo: materias primas y modos de hacer en la alfarería Belén. Aportes desde la petrografía de conjuntos cerámicos del Valle del Bolsón (Belén, Catamarca, Argentina). Estudios Atacameños 43: 71-94.

Puente, V., R. Plá y R. Invernizzi 2014 La alfarería del Tardío Prehispánico del Valle del Bolsón (Catamarca, Argentina): iproducción local o alóctona? Revista del Museo de Antropología 7 (1): 65-78.

Quinn, P. S.

2013 Ceramic Petrography. The Interpretation of Archaeological Pottery \& Related Artefacts in Thin Section. Archaeopress, Oxford.

Raffino, $\mathrm{R}$.

1988 Poblaciones Indígenas Argentinas. TEA, Buenos Aires.

Roux, V.

2003 Ceramic standardization and intensity of production: quantifying degrees of specialization. American Antiquity 68 (4): 768-782.

Rye, $\mathrm{O}$.

1981 Pottery Technology. Principles and reconstruction. Manuals on Archaeology 4. Taraxacum, Washington. 
Spina, J., M. Giovannetti y E. Ferraris

2017 Interrogantes de la metalurgia prehispánica andina. Nuevas propuestas desde los hornos de Quillay (Catamarca, Argentina). Chungara, Revista de Antropología Chilena 49 (3): 327-342.

Stoltman, J. B.

1989 A quantitative approach to the petrographic analysis of ceramic thin sections. American Antiquity 54 (1): $147-160$.

Szilágyi, V. y G. Szakmány

2009 Comparison of volcaniclastic-tempered Inca Imperial ceramic from Paria, Bolivia with potential sources. En Interpreting Silent Artefacts: Petrographic Approaches to Archaeological Ceramics, editado por P. S. Quinn, pp. 211-225. Archaeopress, Oxford.

Valencia M. C., N. Zagorodny y S. M. Rivera 2009 Análisis de restos de madera del sitio Campo de Carrizal, Valle de Hualfín (Catamarca, Argentina). Darwiniana 47 (2): 260-266.

Velde, B. e I. C. Druc 1999. Archaeologic ceramic materials. Origin and utilization. Springer, Verlag Berlín Heidelberg.
Wynveldt, F.

2009 La Loma de los Antiguos de Azampay. Un sitio defensivo del valle de Hualfín (Catamarca, Argentina). Sociedad Argentina de Antropología, Buenos Aires.

Wynveldt, F., B. Balesta y M. E. Iucci

2013 El paisaje tardío del Valle de Hualfín: una reconstrucción arqueológica desde los poblados protegidos. Comechingonia. Revista de Arqueología 17 (2): 191-215.

Wynveldt, F., B. Balesta, M. E. Iucci, C. Valencia y G. Lorenzo

2017 Late chronology in Hualfín Valley (Catamarca, Argentina): a revisión from $14 \mathrm{C}$ dating. Radiocarbon 59 (1): $91-107$.

Zagorodny, N., M. Morosi, M. E. lucci y F. Wynveldt 2010 Estudios composicionales de las pastas de cerámica tardía del Valle de Hualfín (Belén. Catamarca). Arqueología 16: 125-150. 
M. E. Iucci y M. Alperin

136 | Intersecciones en Antropología 20 (1), enero-julio. 2019. ISSN-e 1850-373X 